\title{
DIGITAL SLIDING MODE CONTROLLED THREE-PHASE BOOST INVERTER IMPLEMENTED IN A DSC
}

\author{
Priscila dos Santos Garcia Giacomini ${ }^{1}$, Luiz Carlos de Souza Marques ${ }^{2}$, and Marcello Mezaroba ${ }^{1}$ \\ 1 - Santa Catarina State University - UDESC \\ Mail Box 631, Zip Code: 89.223-100, Joinville, SC, Brazil \\ mezaroba@joinville.udesc.br, priscila@joinville.udesc.br \\ 2 - Santa Maria Federal University - UFSM. \\ Av. Roraima No 1000, Camobi. Zip Code: 97105-900 - Santa Maria - RS - Brazil \\ marques 1csm@hotmail.com
}

\begin{abstract}
This paper presents a Digital Variable Structure Controlled Three Phase Boost Inverter. The main usage of this converter is to provide the necessary AC voltage to a three-phase induction motor from batteries. The variable structure control, which is a hysteresis based control methodology, was implemented using a TMF320F2812 Digital Signal Controller (DSC).

The theoretical analysis, basic equations and the design methodology is presented in this work. The converter's main advantages are only one stage to boost and invert the battery energy and small number of components.
\end{abstract}

Keywords - DC-AC Converter, Three-Phase Boost Inverter, Variable Structure Control.

\section{INTRODUCTION}

In the industry, the direct current (DC) machines have largely lost their popularity in the last years to the alternate current $(\mathrm{AC})$ ones. There are clear preferences for induction machines due to low maintenance, durability and reduced costs.

However, in certain applications, it is not so easy to replace DC machines, like Automatically Guided Vehicles $(\mathrm{AGV})$ and electrical fork lift trucks, used in great part of the industrial environment.

Currently, one of the AGV's problems is the low autonomy of its batteries and the usage of specials machines and converters, which usually have high costs and are difficult to be found.

The topology presented in this paper is an alternative for these vehicles, it is worth noting this topology invert and boost the energy using a single stage, allowing the usage of commons AC machines. In Figure 1 is shown the classic topology and Figure 2 the alternative topology for the AGV's.

To solve the problem about AGV's autonomy, many technical works had been developed. One of those works was a regenerative step-up/step-down DC-DC ZVS PWM converter with active clamping [1]. This converter has the advantage to boost the input voltage to a high output voltage, but it is a DC-DC converter, what mean it is necessary a DC machine or another stage to invert the output voltage.

Manuscript received on 19/10/2007. Revised on 07/03/2008 and 07/06/2008. Accepted by recommendation of the Editor Fernando L. M. Antunes.

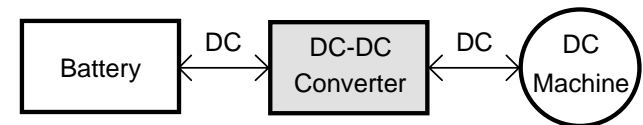

Fig. 1. Classic Power Topology of the AGV

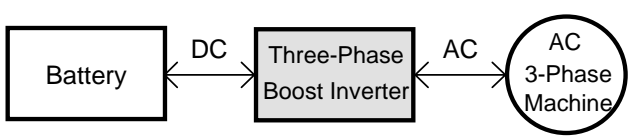

Fig. 2. Alternative Topology of the AGV

The converter presented in this paper has just one stage to boost and invert the output voltage. Many control techniques have been proposed and analyzed to the boost inverter. Among them, there is one based on techniques derived from variable structure system (VSS) theory, like Sliding Mode (SM) control [2-4].

In [5] it is presented a general purpose sliding mode control for DC-DC converter application. In this paper, it was introduced a tutorial on how to calculate the sliding mode parameters and presented examples for Cuk and Sepic converters.

The sliding mode controller for the Boost Inverter is presented in [6-8]. Those implementations had good results but there are some differences between that technique and the one implemented in this article. The main difference is the control previously were analog and implemented in a single phase boost inverter and this one is digitally controlled using the DSC (Digital Signal Controller) TMS320F2812 from Texas Instruments implemented in a three-phase boost inverter.

\section{PRESENTATION OF THE CIRCUIT}

The three-phase boost inverter consists of three current reversible power converters associated. The power converter used in this work has the same switches number as a regular inverter, with the addition of the input inductors that are necessary to step-up the input voltage.

The power topology is presented in Figure 3 and the output phase voltages and line voltages waveforms of this converter can be observed in Figure 4.

The output voltage is the same in the three phases but with $120^{\circ}$ delay between them. The signal is composed of a DC signal plus a sinusoidal waveform, as it is presented in (1).

$$
\begin{aligned}
& v U=V_{D C}+\sqrt{2} \cdot V_{0} \cdot \sin (\omega t) \\
& v V=V_{D C}+\sqrt{2} \cdot V_{0} \cdot \sin \left(\omega t-120^{\circ}\right) \\
& v W=V_{D C}+\sqrt{2} \cdot V_{0} \cdot \sin \left(\omega t-240^{\circ}\right)
\end{aligned}
$$




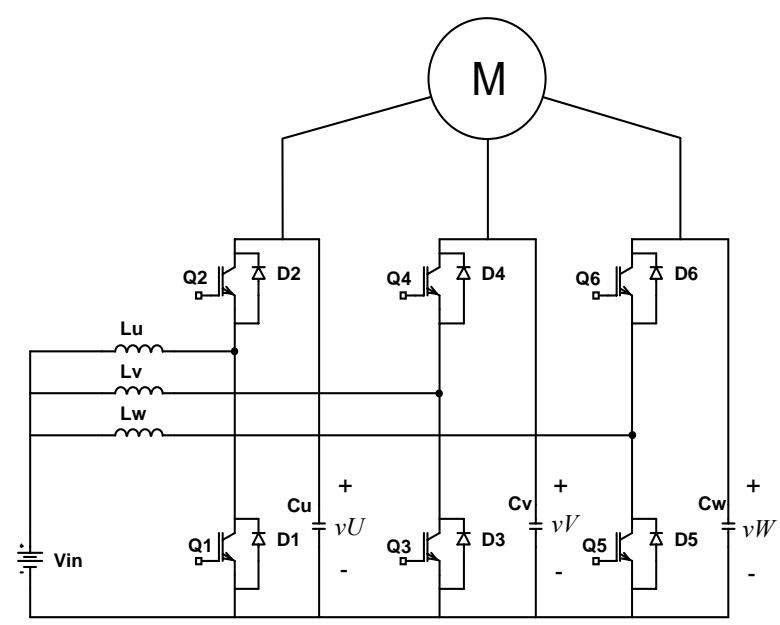

Fig. 3. Three - Phase Boost Inverter

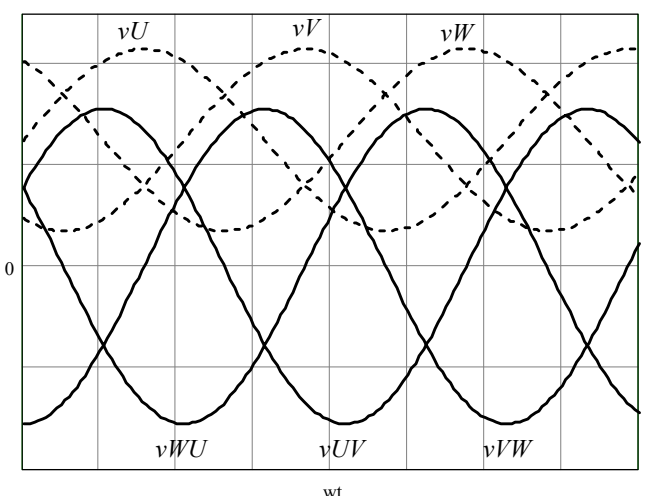

Fig. 4. Three-Phase Boost Inverter's Main Waveforms

The initial specifications of this project and the main results can be observed in TABLE I and TABLE II respectively. It is worth noting to design the components, the converter was considered to be operating using the PWM (Pulse Width Modulation) technique.

TABLE I - Initial Specifications

\begin{tabular}{ll}
\hline$V_{\text {in }}=48 \mathrm{Vdc}$ & Input Nominal Voltage \\
\hline$V_{U, V, W}=127 \mathrm{~V}$ & Phase Voltage \\
\hline$V_{U V, V W, W U}=220 \mathrm{~V}$ & Line Voltage \\
\hline$P_{\text {out }}=3 \mathrm{cv}(2208 \mathrm{~W})$ & Output Nominal Power \\
\hline$\Delta I i=20 \%$ & Input Current Ripple \\
\hline$\Delta V o=5 \%$ & Output Voltage Ripple \\
\hline$F_{s}=20 \mathrm{kHz}$ to $50 \mathrm{kHz}$ & Switching Frequency \\
\hline
\end{tabular}

TABLE II - Main Results

\begin{tabular}{ll}
\hline Lin $=130 \mu \mathrm{H}$ & Input Inductor \\
\hline Cout $=20 \mu \mathrm{F}$ & Output Capacitor \\
\hline Iin_max $=83 \mathrm{~A}$ & Maximum Input Current \\
\hline Iin_min $=-30 \mathrm{~A}$ & Minimum Input Current \\
\hline
\end{tabular}

\section{CONTROL}

The variable structure control has been presented as a good alternative to control switching power converters [910]. Some advantages over classic controllers are the stability on supply and load variations, robustness, good dynamic response and simple implementation.

The posterior analysis and control block diagram are designed for a single phase, due to the three phases are symmetrical. Figure 5 shows the control block diagram. In this figure it is worth noting there is no electrical current reference because this variable is not directly controlled. The current error is obtained using a high-pass filter.

The control methodology uses a hysteresis based on the error variables, where the voltage error is not enough to control the power converter, so the input current ripple helps the control to impose the correct switch during the converter operation. It is important to observe that just the input current is used on the control and its rms value will depend on the load applied to the system.

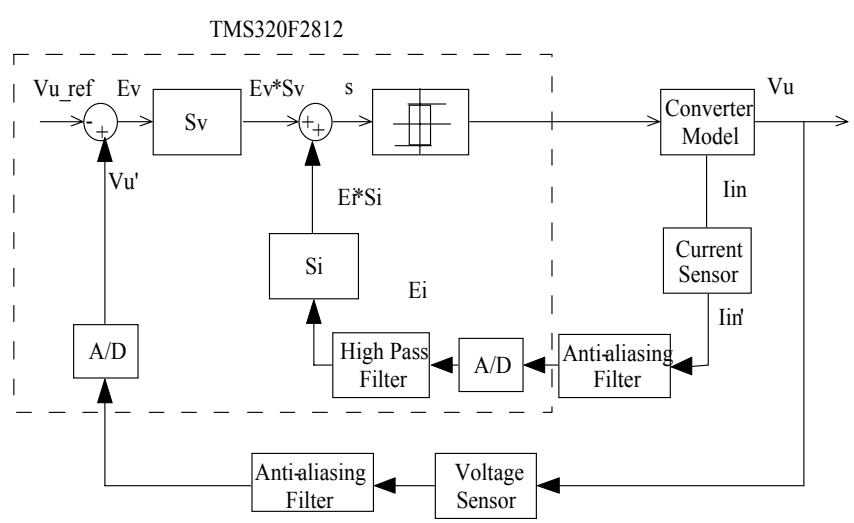

Fig. 5. Control Block Diagram

\section{A. Control Design Methodology}

The first stage to design the variable structure control is to find the boost state-space model. The load of the converter is considered linear. In the first stage, $\mathrm{Q}_{1}$ is open and $\mathrm{Q}_{2}$ is closed and in the second stage, $\mathrm{Q}_{2}$ is open and $\mathrm{Q}_{1}$ is closed. The state-space modeling of the equivalent circuit with state variables $i_{L}$ (input inductor current) and $v C$ (output capacitor voltage) is given by (2).

$\left[\begin{array}{c}\frac{d V_{c}}{d t} \\ \frac{d i_{L}}{d t}\end{array}\right]=\left[\begin{array}{cc}\frac{-1}{R C} & \frac{1}{C} \\ \frac{-1}{L} & 0\end{array}\right] \cdot\left[\begin{array}{c}V_{C} \\ i_{L}\end{array}\right]+\left[\begin{array}{c}\frac{-i_{L}}{C} \\ \frac{V_{C}}{L}\end{array}\right] \cdot \gamma+\left[\begin{array}{c}0 \\ \frac{V_{i n}}{L}\end{array}\right]$

Where:

$$
\begin{aligned}
& \gamma=\left\{\begin{array}{l}
1 \text { when } Q_{1} \text { on } / Q_{2} \text { off } \\
0 \text { when } Q_{1} \text { off } / Q_{2} \text { on }
\end{array}\right. \\
& V_{C}=V_{U}=V_{V}=V_{W}=\text { Output Voltage } \\
& I_{L}=I_{U}=I_{V}=I_{W}=\text { Input Current }
\end{aligned}
$$


$\mathrm{C}=C_{U}=C_{V}=C_{W}=$ Output Capacitor

$\mathrm{L}=L_{U}=L_{V}=L_{W}=$ Input Inductor

$\mathrm{R}=\mathrm{Load}$

It is important to note the equations above can be represented by (3).

$$
\frac{d x}{d t}=A \cdot x+B \cdot \gamma+C
$$

The switching surface equation in the state space is expressed by a linear combination of the space-state variable errors and it can be observed in (4).

$$
\sigma\left(v C, i_{L}\right)=s_{v} \cdot \varepsilon_{V}+s_{i} \cdot \varepsilon_{i}
$$

Where:

$$
\begin{aligned}
& \varepsilon_{V}=v C-v C_{r e f} \\
& \varepsilon_{i}=i_{L}-i_{\text {Lref }}
\end{aligned}
$$

Replacing (5) in (3), the equation can be redefined by (6).

$$
\frac{d \varepsilon}{d t}=A \cdot \varepsilon+B \cdot \gamma+D
$$

Where:

$$
D=\left[\begin{array}{cc}
\frac{i_{L_{-} r e f}}{C} & \frac{-V_{C_{-} r e f}}{R C} \\
\frac{V_{\text {in }}}{L} & \frac{-V_{C_{-} r e f}}{L}
\end{array}\right]
$$

To find the switching surface gains, it is necessary to plot both of structures and find the best rate between $\mathrm{s}_{\mathrm{i}}$ and $\mathrm{s}_{\mathrm{v}}$. The status of the switching is related to the value of $\sigma(x)$.

$$
\gamma=\left\{\begin{array}{l}
0 \rightarrow \sigma>0 \\
1 \rightarrow \sigma<0
\end{array}\right.
$$

In Figure 6 it is possible to observe the structure $1 \quad(\gamma=1)$ space-state plane. Figure 7 presents the space-state plane to structure $2(\gamma=0)$.

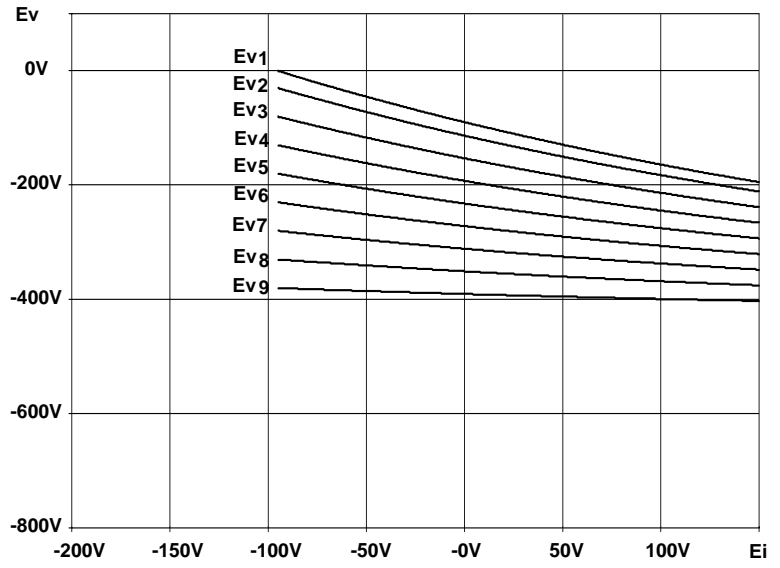

Fig. 6. Structure 1

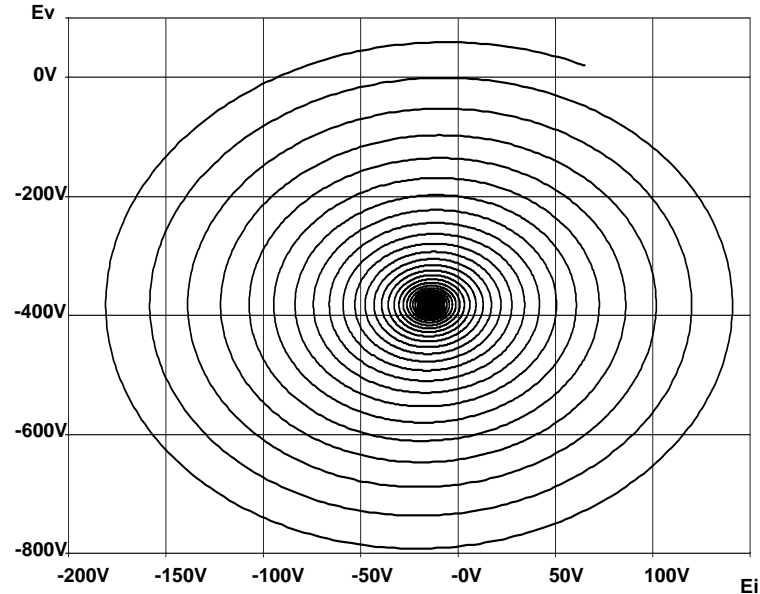

Fig. 7. Structure 2

It is important to note that the structure 1 just can work when $\mathrm{vC}>$ Vin, so $\varepsilon \mathrm{v}>-\left(v C_{r e f}-V i n\right)$.

The combined state-space plane is presented in Figure 8.

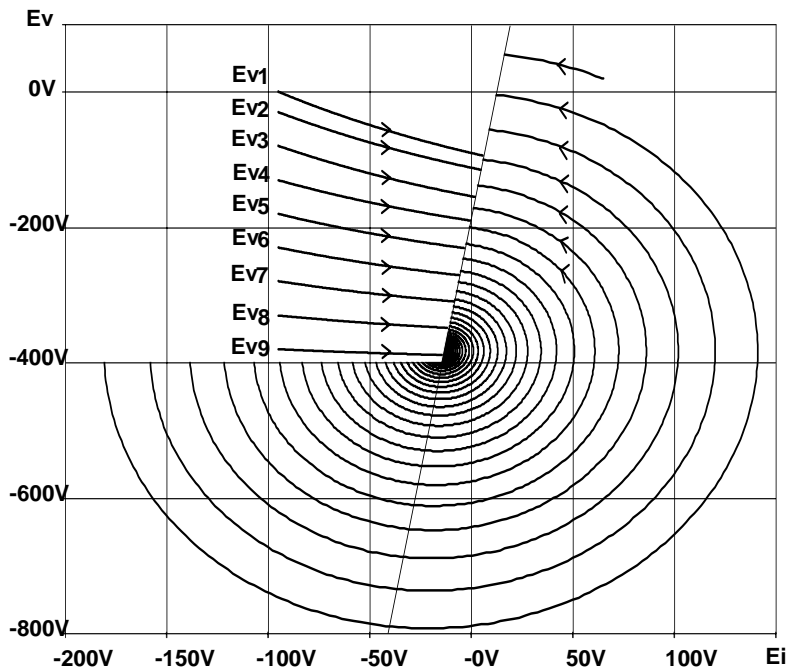

Fig. 8. Combined space-state planes

The switching surface rate was chosen to provide the best performance of the control. Two auxiliary operation points were necessary to find the switching function: the initial and final one.

So, the rate between $s_{i}$ and $s_{v}$ is 0,12 . Considering $s_{i}=0,1$ :

$$
\begin{aligned}
& \frac{S_{v}}{S_{i}}=0,12 \\
& S_{v}=0,012
\end{aligned}
$$

\section{B. Switching Frequency}

The state trajectories are directed toward the switching surface and move to another structure in the same moment, only if the switching frequency is infinite. It is not possible in practical systems, so a typical control circuit features a hysteresis comparator with width $2 \delta$ is implemented as it can be observed in Figure 9. 


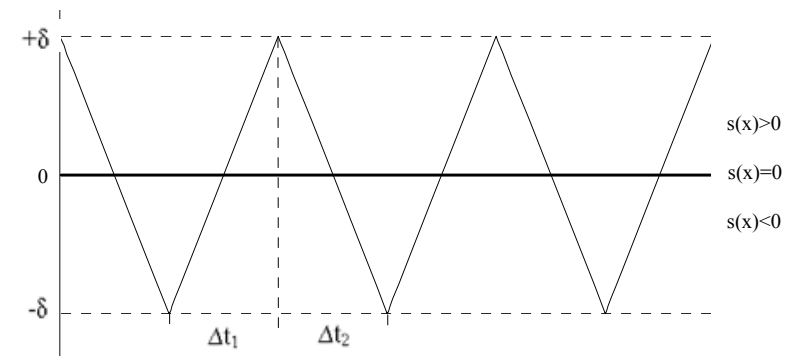

Fig. 9. S(x) Behavior

The switching frequency is shown in (9), where $\Delta t_{1}$ is the conduction time of the switch $\mathrm{Q}_{1}$ and $\Delta \mathrm{t}_{2}$ is the conduction time of the switch $\mathrm{Q}_{2}$.

$$
f s=\frac{1}{\Delta t_{1}+\Delta t_{2}}
$$
(10).

The times quantities for $\Delta \mathrm{t}_{1}$ and $\Delta \mathrm{t}_{2}$ can be found using

$$
\frac{d s}{d t}=\frac{\Delta s}{\Delta t}
$$

Using (10) it is possible to find an equation to represent $\Delta \mathrm{t}_{1}$ and $\Delta \mathrm{t}_{2}$.

$$
\begin{gathered}
\Delta t_{1}=\frac{2 \delta}{s_{v} \cdot\left(\frac{-v C_{r e f}}{R \cdot C}\right)+s_{i} \cdot\left(\frac{V_{i n}}{L}\right)} \\
\Delta t_{2}=\frac{-2 \delta}{s_{v} \cdot\left(\frac{i_{\text {Lref }}}{C}-\frac{v C_{r e f}}{R \cdot C}\right)+s_{i} \cdot\left(\frac{V_{i n}}{L}-\frac{v C_{r e f}}{L}\right)}
\end{gathered}
$$

The maximum switching frequency is obtained when the converter is operating without load $\left(i_{\text {Lref }}=0\right.$ and $\left.\mathrm{R}=\infty\right)$ and it can be obtained replacing (11) and (12) in (9).

$$
f_{s_{-} \max }=\frac{s_{i} \cdot V_{\text {in }}}{2 \cdot \delta \cdot L}\left(1-\frac{V_{\text {in }}}{v C_{\text {ref }}}\right)
$$

\section{Flowchart}

A flowchart was designed to help and make easier the source code creation.

The main code is just to configure all the peripherals, clocks and create the variables used in the control. The software has an ADC interrupt after each ADC conversion. In the interrupt routine, the sliding mode control is implemented and the switches pulses are created. If an error signal from the drivers reaches the DSC, the external interrupt occurs and all the switches are opened. Figure 10 shows the main flowchart. The external and ADC interrupts flowcharts can be observed in Figure 11 and Figure 12.

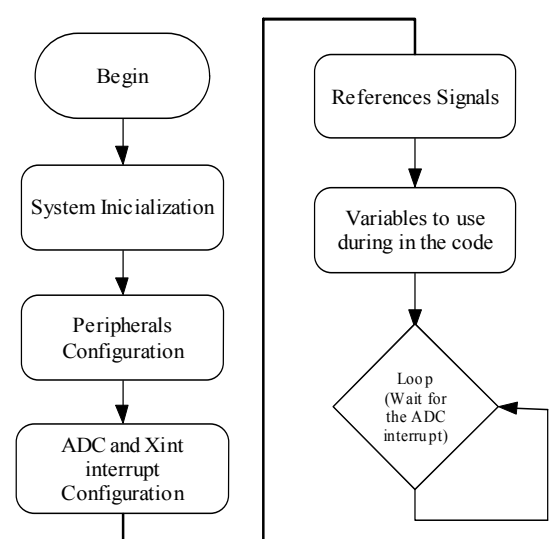

Fig. 10. Main Flowchart

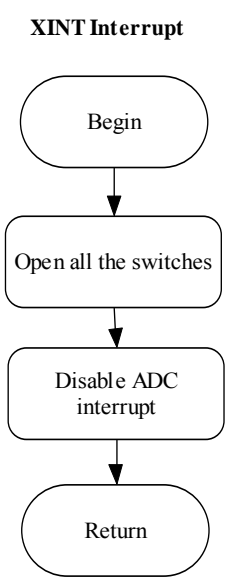

Fig. 11. External Interrupt Flowchart

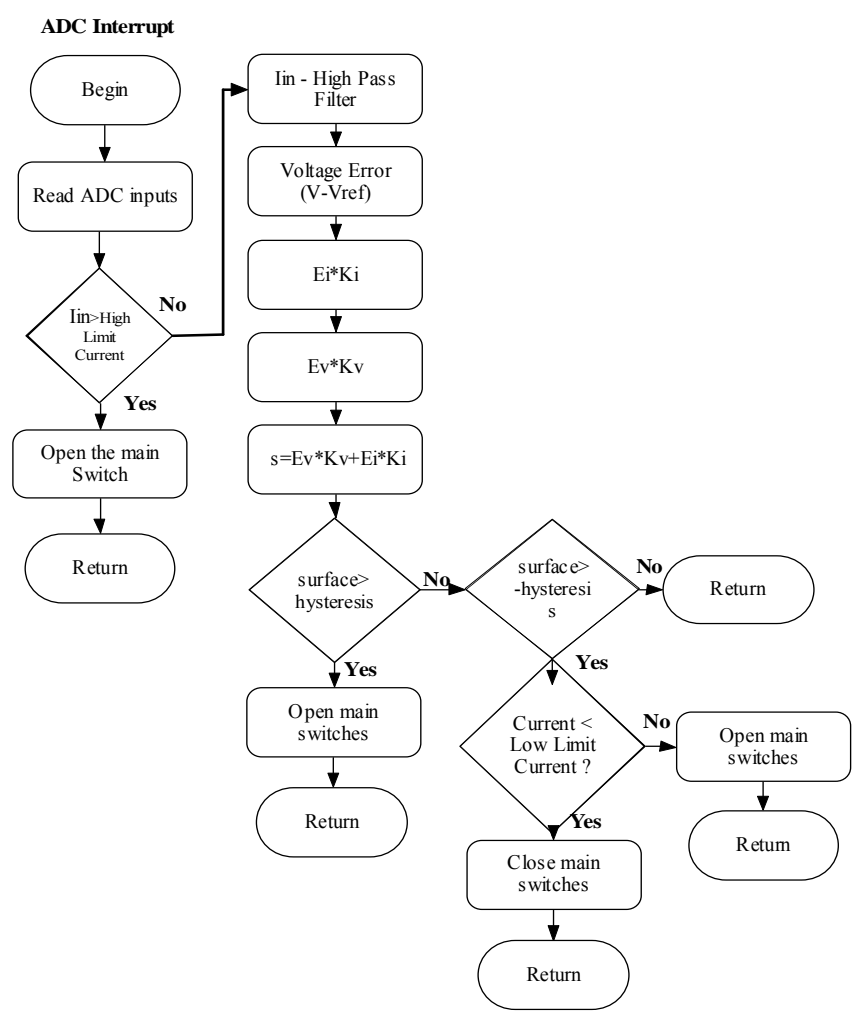

Fig. 12. ADC Interrupt 


\section{EXPERIMENTAL RESULTS}

\section{A. Simulation Results}

In order to validate the theoretical analysis, the variable structure controlled three-phase boost inverter was simulated using the package Simulink from the software Matlab. Figure 13 shows the output voltages using $3.33 \mu$ s sample period.

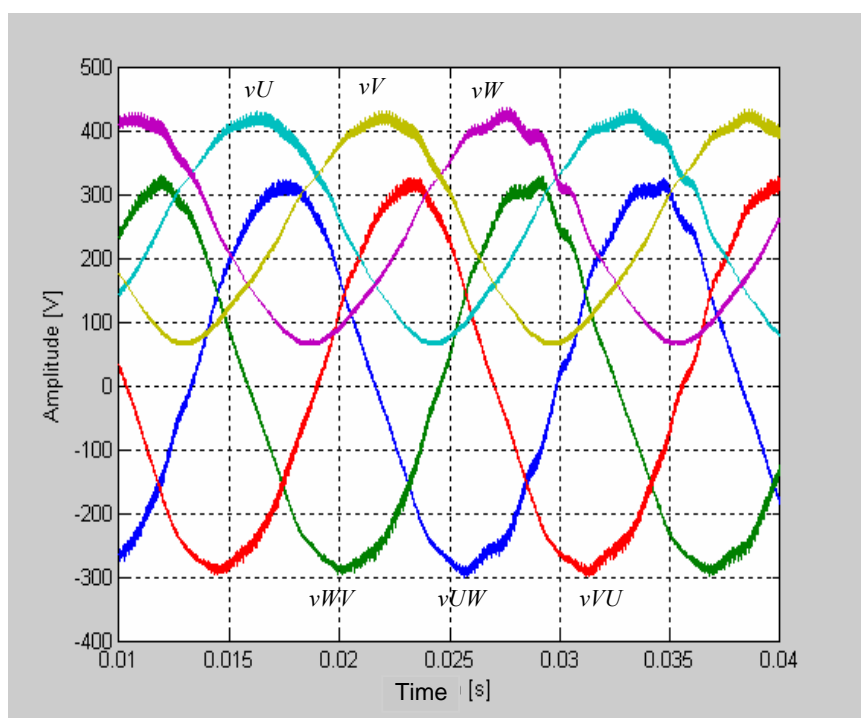

Fig. 13. Output Voltages

In Figure 14 is shown the input current in one of the phases. The current in other phases is similar, just with a $120^{\circ}$ delay.

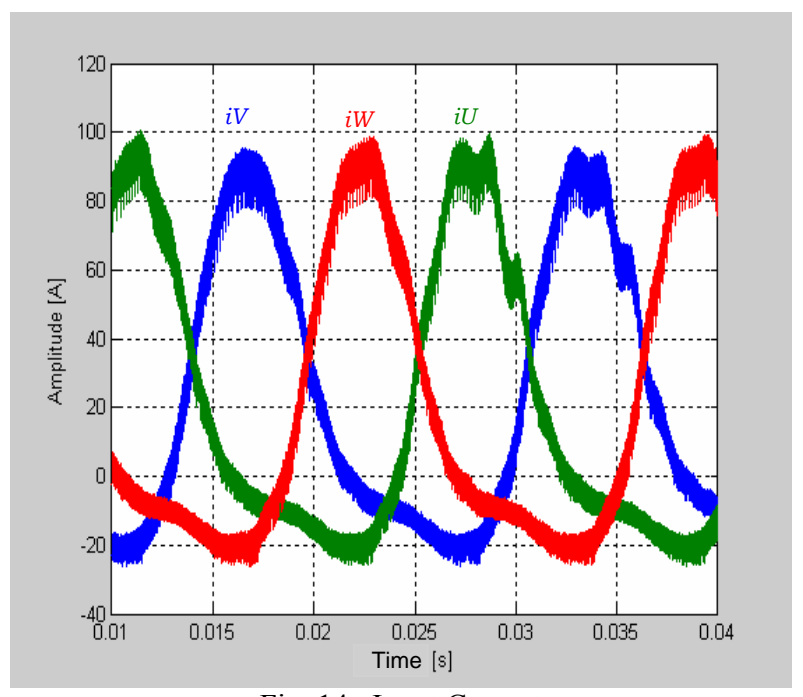

Fig. 14. Input Current

\section{B. Prototype}

After to design the control and validate its efficiency by simulations, a prototype was build to acquire experimental results.

The control was digitally implemented using a DSC and some signal conditioning was necessary to assure good accuracy in the analogical to digital conversion.
Figure 15 shows the main blocks of the system, as DSC, power converter, anti-aliasing filters, signal conditioners and so one.

The voltage sensors used in this prototype were resistive dividers. They were chosen due to their costs and no isolation requirements. Due to the reference used in the control and the structure itself, the sensors used to measure the input currents were isolated Hall-Effect sensors.

The anti-aliasing filters avoid the spectrum superposition on sampled systems. The cut-off frequency of the antialiasing filter of the voltage feedback signal is approximately $120 \mathrm{~Hz}$ and the current feedback signal is approximately $150 \mathrm{kHz}$

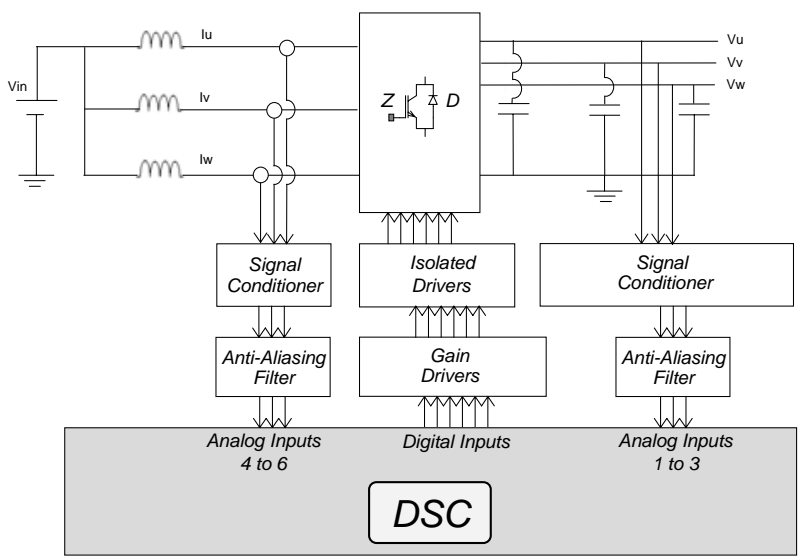

Fig. 15. Converter Block Diagram

The developed software was created to calculate the variables involved in the control technique at $300 \mathrm{kHz}$ using the Analog to Digital Interruption. The current sample is filtered using an IIR (Infinite Impulse Response) digital filter to keep just the electrical current ripple. The voltage sample is compared with the current voltage reference vector position and reserved to the later calculations. The voltage reference vector was created using 380 positions and by this reason, its index is incremented each 13 interruptions.

Using the voltage error and the filtered current, the switching surface gains are applied as presented in Figure 5, and sent to the hysteresis comparator. Using the output hysteresis comparator, the states switches are updated.

Some special features were created to allow the corrected operation of the system. A soft-start procedure was implemented to boost the output voltage for 3 intermediate levels using a ladder profile before applying the nominal voltages references in order to eliminate electrical current peaks. An electrical current limitation is applied each cycle, avoiding current peaks higher than maximum under nominal operation. During the software development, special routines were implemented to allow the developer to stop the processor being sure the main switches were opened and will not cause any damage to the system.

The whole encoding was done using $\mathrm{C}$ language and the libraries available in the processor's manufacturer website. In order to be sure the compiler were not using too much assembly for each $\mathrm{C}$ language encoded line, the generated assembly code was verified for the whole control technique related code. 


\section{Experimental Results}

Experimental results were obtained using the prototype specified in Table I. The results presented in this section were obtained using a full load.

Figure 16 shows the three output voltage and Figure 17 shows the line voltages. In this condition, the THD of $v \mathrm{UV}$, $v \mathrm{VW}$ and $v \mathrm{WU}$ was $5.4 \%, 5.4 \%$ and $4.9 \%$ respectively. In Figure 18 it is possible to observe the motor current.

Other important waveform that should be observed is the inductor current that is presented in Figure 19.

To assure the control technique, two different frequencies in voltage reference signal were applied. The Figure 20 and Figure 21 present the output voltage with different frequencies.

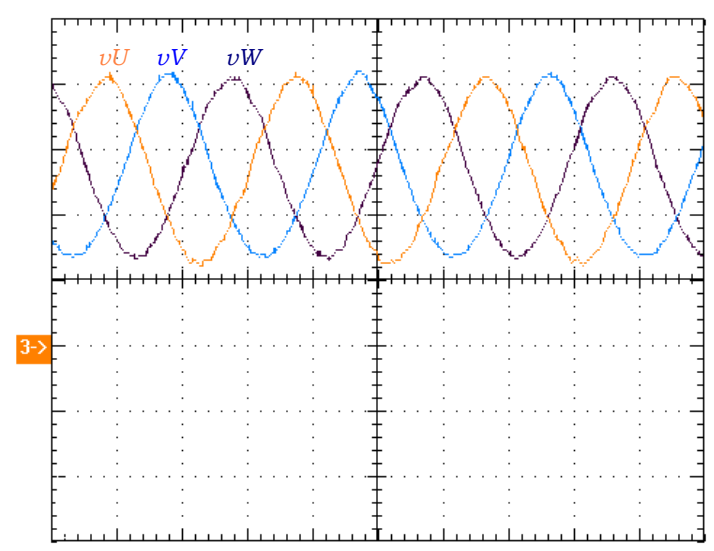

Fig. 16. Output Voltage (100V/div, 5ms)

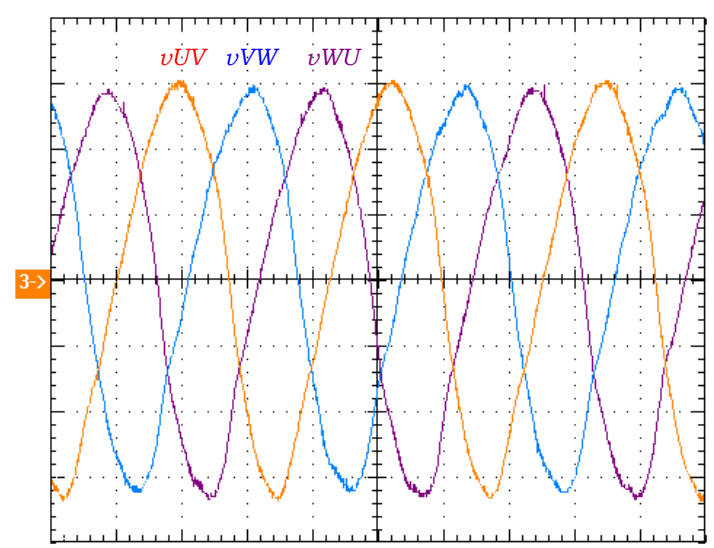

Fig. 17. Line Voltages (100V/div, 5ms)

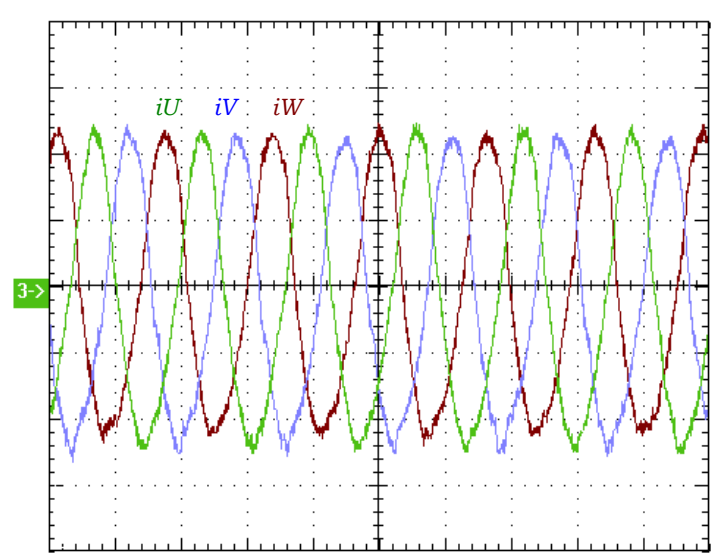

Fig. 18. Motor Current (2A/div, 10ms)

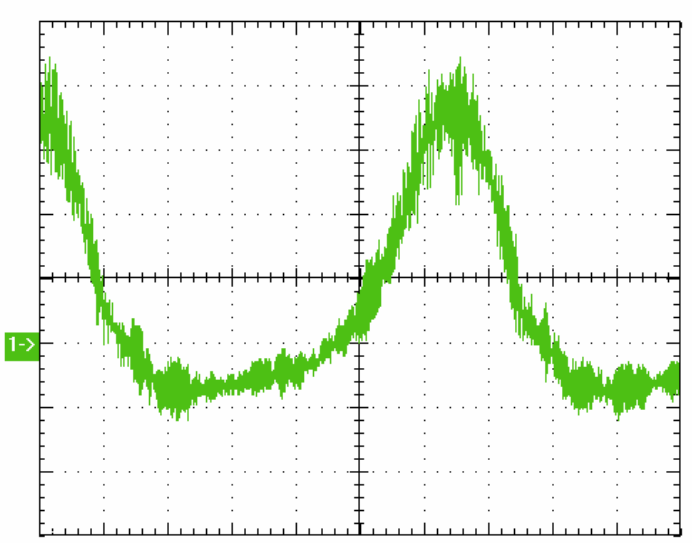

Fig. 19. Inductor Current (10A/div, 2.5ms)

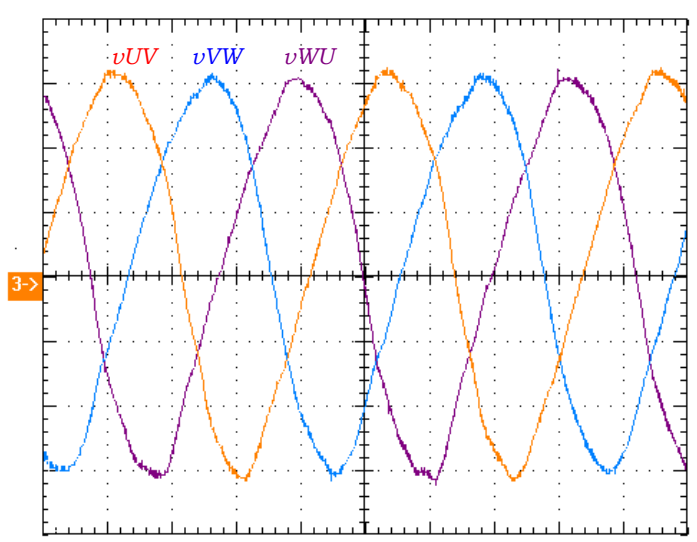

Fig. 20. Line Voltages $-45 \mathrm{~Hz}(100 \mathrm{~V}, 5 \mathrm{~ms})$

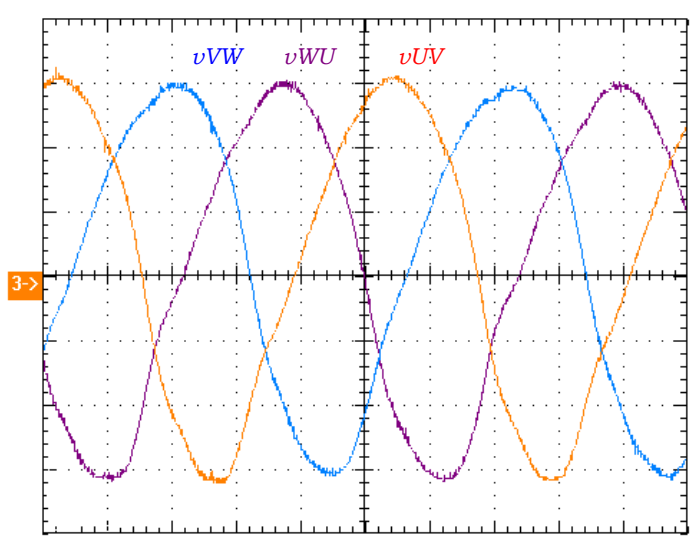

Fig. 21. Line Voltages $-75 \mathrm{~Hz}(100 \mathrm{~V}, 2.5 \mathrm{~ms})$

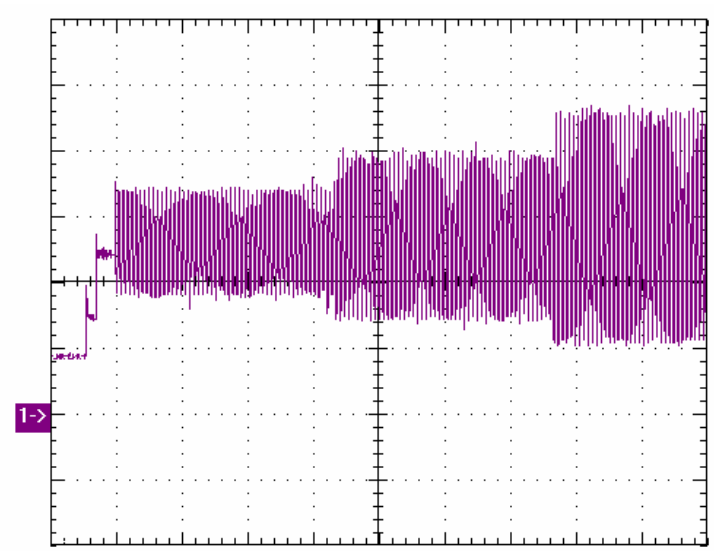

Fig. 22. Soft Start of the Motor (100V/div, 250ms) 
It is important to note that in the start of the motors, the current is very high. So, to minimize that, the algorithm was developed to purpose a soft start to the motor where two different DC levels are applied to the converter output and after that the AC signal starts with small amplitude and it should getting high until the nominal amplitude. The soft start voltage of the motor is presented in Figure 22.

\section{CONCLUSION}

This paper presented a Digital Variable Structure Controlled Three-Phase Boost Inverter and its theoretical analysis with the main equations of its control.

In order to validate the theoretical analysis, the circuit was simulated and implemented as a $2.2 \mathrm{~kW}$ prototype. The experimental output voltages, input currents and switching behavior waveforms closely matched the theoretical ones. One advantage of digital variable structure control is its easy code creation and facility to adjust the practical gains. On the other hand, by the reason that this control technique is based on hysteresis, the processor should be very fast to be able to process a great number of samples and compare it with the hysteresis. In practical experiments the authors conclude that is necessary a sampling frequency at least 6 times greater that the maximum switching frequency to obtain a good control response.

The nominal results were acquired with a $90 \mathrm{Vdc}$ input voltage. It was necessary because it is not possible to get the nominal power with $48 \mathrm{Vdc}$, due to the non linear characteristic of the boost inverter, mainly for high gains.

\section{ACKNOWLEDGEMENT}

The authors gratefully acknowledge the donation of the EzDSP2812 development kit from Texas Instruments, the output capacitors from WEG Industry - Brazil and the input toroidal inductors from Magmatech - Brazil. Santa Catarina State University financial support with a scholarship is also gratefully acknowledged.

\section{REFERENCES}

[1] M. Mezaroba, P. S. G. Giacomini, J. S. Scholtz. "Conversor Elevador/Abaixador com Comutação Suave ZVS PWM e Grampeamento Ativo". INDUSCON Conferência Internacional de Aplicações Industriais. Bahia - Brazil, 2006.

[2] V. I. Utkin, "Sliding Modes in Control Optimization". ISBN 3-540-53516-0. Berlin 1992.

[3] U. Itkin, "Sliding Modes and Their Application in Variable Structure Systems". MIR Pub., Moscow, 1974.

[4] R. Venkataramanan, A. Sabanovic, S. Cuk. "Sliding Mode Control of DC to DC Converters"; pp. 251 - 258, IECON, 1985.

[5] P. Mattavelli, L. Rossetto, G. Spiazzi, "General Purpose Sliding - Mode Controller for DC/DC Converter Applications". 25th Annual IEEE Power Electronics Specialist Conference, pp. 609-615, 1993.

[6] R. O. Cáceres, I. Barbi, "A Boost DC-AC Converter: Analysis design, and Experimentation." IEEE Transactions on Power Electronics, pp. 134-140, 1999.
[7] R. Cáceres, I. Barbi, "Sliding Mode Controller for the Boost Inverter". CIEP - International Power Electronics Congress, pp. 247-252, 1996.

[8] S.A. Bock, J.R. Pinheiro, H, Gründling, H.L. Hey, H. Pinheiro. "Existence and Stability of Sliding Modes in Bi-directional DC - DC Converters". 32nd Annual IEEE Power Electronics Specialist Conference, pp. 1283 - 1288, 2001.

[9] H. Sira-Ramirez. "Sliding Mode Control for AC to DC Converters". CBA 88 - Congresso Brasileiro de Automática, pp. 21-26, 1988.

[10] H. Pinheiro, A. Martins, J. Pinheiro. "Single Phase Voltage Inverters Controlled by Sliding Mode". CBA 94 - Congresso Brasileiro de Automática, pp. 11771182,1994

[11] J.Y. Hung, W. Gao, J. C. Hung, "Variable Structure Control: A Survey". IEEE Transaction on Industrial Electronics, Volume: 40, Issue 1, pp 2-22, 1993.

[12] W. M. Pastorello Filho, N. Batistela, A. J. Perin. "Controle por Modos Deslizantes Aplicado a Conversores Estáticos de Potência”. SEP - Seminário de Eletrônica de Potência - UFSC, 1995.

[13] R. O. Cáceres I. Barbi, "Família de Conversores CC $C A$, Derivados dos Conversores CC - CC Fundamentais". Tese de Doutorado. UFSC, 1997.

[14] I. E. Colling, "Conversores CA - CC Monofásicos e Trifásicos Reversíveis com Elevado Fator de Potência". Tese de Doutorado. UFSC, 2000.

[15] Z. Radulovic and A. Sabanovic, "Active filter control using a sliding mode approach," Proc. PESC'94, pp. 177-182, 1994.

[16] H. J. Sira-Ramirez and M. Rios-Bolívar, "Sliding Mode Control of DC-to-DC Power Converters Via Extended Linearization," IEEE Trans.Circuits Syst. I, Fundam. Theory Appl., vol. 41, no. 10, pp. 652-661, Oct. 1994

[17] S. Saetieo, R. Devaraj, and D. A. Torrey, "The Design and Implementation of a Three-Phase Active Power Filter Based on Sliding Mode Control," IEEE Trans. Ind. Appl., vol. 31, no. 5, pp. 993-1000, 1995.

[18] S. C. Tan, Y. M. Lai, C. K. Tse, and M. K. H. Cheung, "Adaptive Feedforward and Feedback Control Schemes for Sliding Mode Controlled Power Converters," IEEE Trans. Power Electron., vol. 21, no. 1, pp. 182-192, 2006.

[19] J. Matas, L.G. de Vicuna, J. Miret, J.M. Guerrero, M. Castilla; "Feedback Linearization of a Single-Phase Active Power Filter via Sliding Mode Control". IEEE Transactions on Power Electronics, Vol. 23, Issue 1, pp. 116 - 125, 2008.

[20] Faa-Jeng Lin; Chih-Kai Chang; Po-Kai Huang; "FPGABased Adaptive Backstepping Sliding-Mode Control for Linear Induction Motor Drive". IEEE Transactions on Power Electronics, Volume 22, Issue 4, pp 1222 1231, July 2007.

[21] M. S. Kaster and D. J. Pagano; "Geração de oscilações auto-sustentadas em inversores monofásicos". Sba Controle \& Automação, vol.17 No. 1, Campinas Jan/Mar. 2006 


\section{BIOGRAPHIES}

Priscila dos Santos Garcia Giacomini was born in Joinville, SC, Brazil, on December 8, 1981. She received the B.S and M.S degrees in electrical engineering from State University of Santa Catarina, Joinville, SC, Brazil, in 2005 and 2007 respectively. She is currently working in products development area at Weg Industry S.A, Jaraguá do Sul, SC, Brazil

Luiz Carlos de Souza Marques received the M.S. and the Ph.D. degrees in electrical engineering from the Federal
University of Santa Catarina, Florianópolis, SC, Brazil, in 1996 and 2001, respectively. $\mathrm{He}$ is presently Titular Professor in the Department of Electrical Engineering at Federal University of Santa Maria, Brazil.

Marcello Mezaroba was born in Videira, SC, Brazil, on November 20, 1972. He received the B.S., M.S. and the $\mathrm{Ph} . \mathrm{D}$. degrees in electrical engineering from the Federal University of Santa Catarina, Florianópolis, SC, Brazil, in 1996, 1998 and 2001, respectively. He is presently Professor in the Department of Electrical Engineering at State University of Santa Catarina, Brazil. 